VALMIR JESUS DOS SANTOS

\title{
Coreutas de Barão Geraldo: uma transversal do Teatro de Grupo no distrito de Campinas
}

Dissertação apresentada ao Programa de Pós-Graduação em Artes Cênicas, área de concentração Teoria e Prática do Teatro, linha de pesquisa História do Teatro da Escola de Comunicações e Artes da Universidade de São Paulo, como exigência parcial para obtenção do Título de Mestre em Artes, sob orientação da Prof ${ }^{a}$. Dr ${ }^{a}$. Sílvia Fernandes da Silva Telesi. 


\section{Coreutas de Barão Geraldo: uma transversal do Teatro de Grupo no distrito de Campinas}

Dissertação apresentada ao Programa de Pós-Graduação em Artes Cênicas, área de concentração Teoria e Prática do Teatro, linha de pesquisa História do Teatro da Escola de Comunicações e Artes da Universidade de São Paulo, como exigência parcial para obtenção do Título de Mestre em Artes, sob orientação da Profa. Dra. Sílvia Fernandes da Silva Telesi. 
Comissão Julgadora, em 11 de maio de 2009:

Prof $^{a}$. Dra ${ }^{\mathrm{a}}$. Silvia Fernandes da Silva Telesi

Prof $^{\mathrm{a}}$ Dra $^{\mathrm{a}}$ Maria Thais Lima Santos

Prof $^{\circ}$ Dr $^{\circ}$ Cassiano Sydow Quilici 


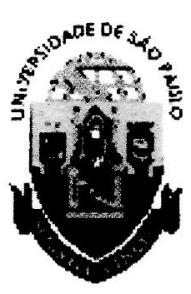

Janus

\section{Universidade de São Paulo}

\section{RELATÓRIO DE DEFESA}

Aluno: 27156 - 4969784 - 1 / Página 1 de 1

Relatório de defesa pública de Dissertação do(a) Senhor(a) Valmir Jesus dos Santos no Programa: Artes Cênicas, do(a) Escola de Comunicações e Artes da Universidade de São Paulo.

Aos 11 dias do mês de maio de 2009, no(a) realizou-se a Defesa da Dissertação do(a) Senhor(a) Valmir Jesus dos Santos, apresentada para a obtenção do título de Mestre intitulada:

"Coreutas de Barão Geraldo: uma transversal do Teatro de Grupo no distrito de Campinas"

Após declarada aberta a sessão, o(a) Sr(a) Presidente passa a palavra ao candidato para exposição e a seguir aos examinadores para as devidas arguições que se desenvolvem nos termos regimentais. Em seguida, a Comissão Julgadora proclama o resultado:

$\begin{array}{llll}\text { Nome dos Participantes da Banca } & \text { Função } & \text { Sigla da CPG } & \text { Resultado } \\ \text { Silvia Fernandes da Silva Telesi } & \text { Presidente } & \text { ECA - USP } & \text { apeovedo } \\ \text { Maria Thais Lima Santos } & \text { Titular } & \text { ECA - USP } & \text { aprovedo } \\ \text { Cassiano Sydow Quilici } & \text { Titular } & \text { PUC-SP - Externo Gplovado }\end{array}$

\section{Resultado Final:}

\section{Parecer da Comissão Julgadora *}

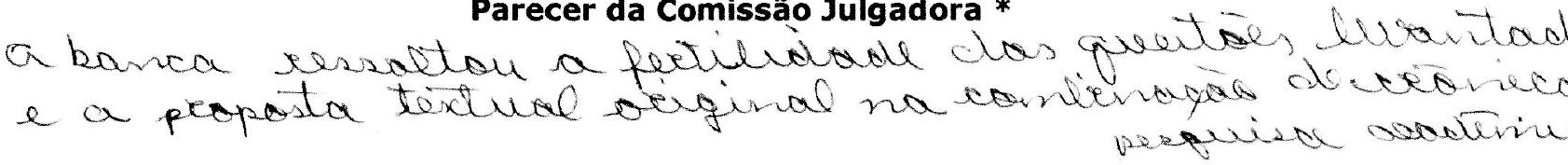

Eu, , lavrei a presente ata, que assino juntamente com os(as)

Senhores(as). São Paulo, aos 11 dias do mês de maio de 2009.
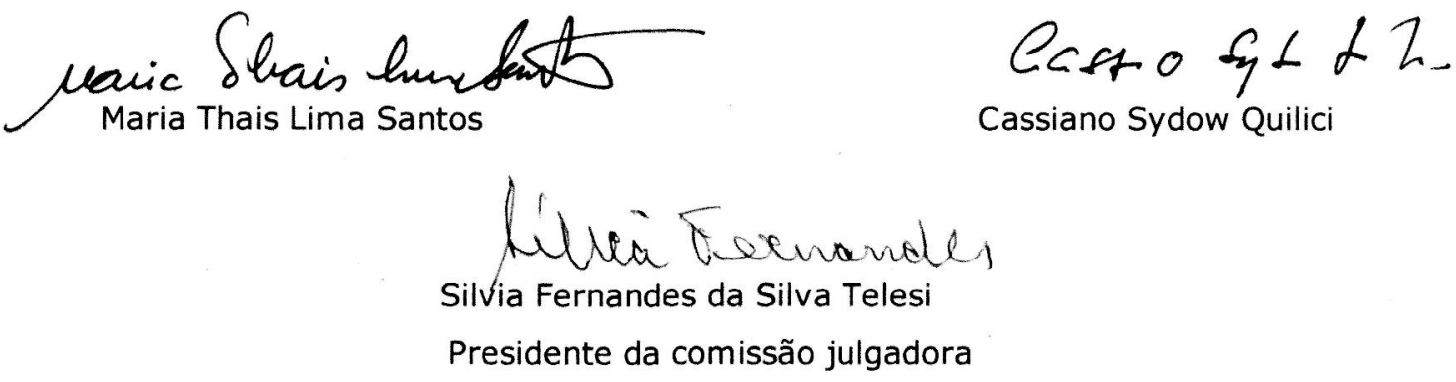

* Obs: Se o candidato for reprovado por algum dos membros, o preenchimento do parecer é obrigatório.

O título foi homologado pela Comissão de Pós-Graduação em e, portanto, o(a) aluno(a) faz jus ao título de Mestre em Artes obtido no Programa Artes Cênicas - Área de concentração: Teoria e Prática do Teatro. 


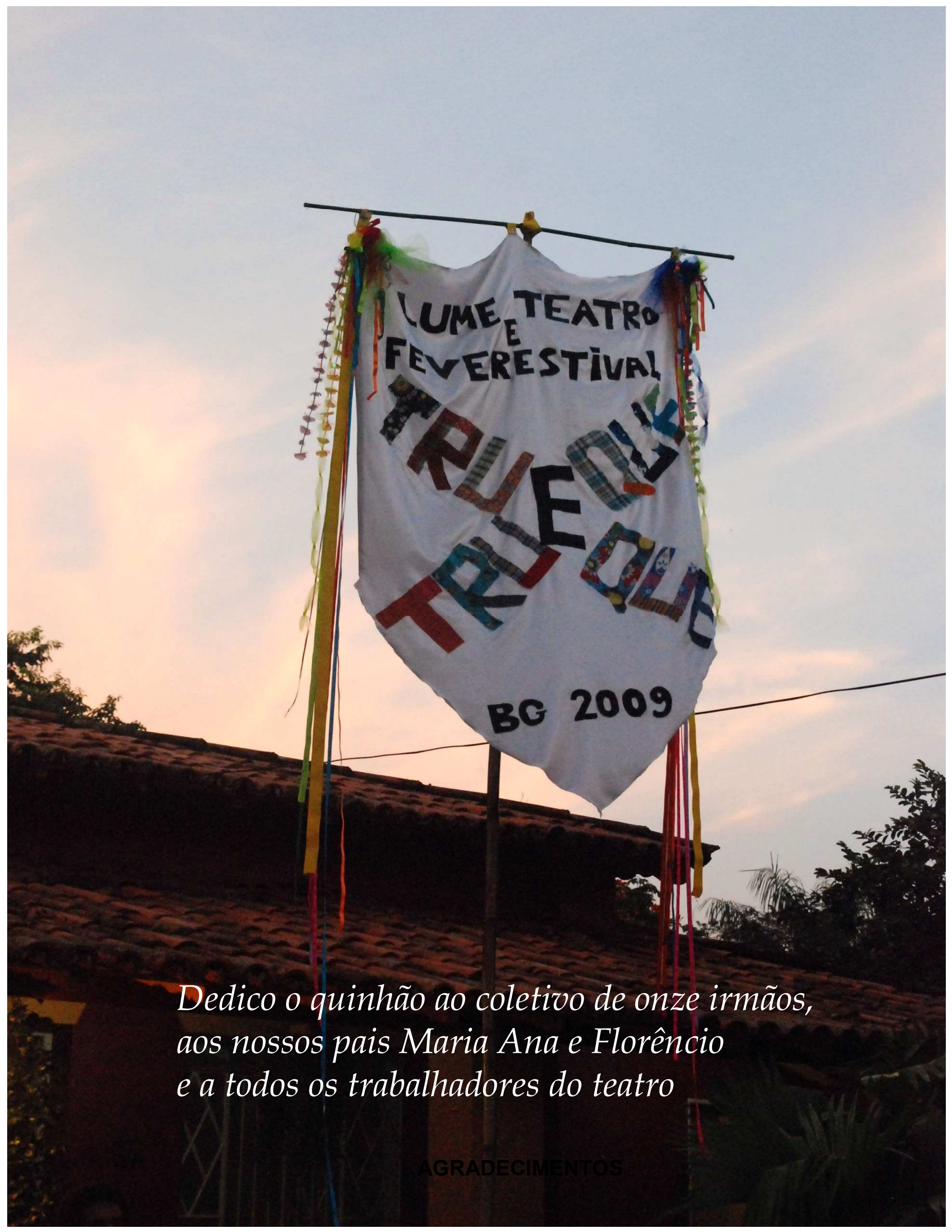

Estandarte do Trueque, 20 fev. 2009, por Bukke Reis. 


\section{AGRADECIMETOS}

À orientadora Silvia Fernandes, pela cumplicidade incondicional.

E aos amigos que contracenam: Ana Lúcia Ferraz, Andréa Barbosa, Beth Néspoli, Carlota Cafiero, Cecilia Luedemann, Cláudio Capitão, Danilo Vasques, Eliane José, Fernando Campos, Hevlyn Celso, Íris Cavalcanti, Ivana Moura, Jaime Kuk, Kil Abreu, Lenise Pinheiro, Lindiane Moretti, Lino Rojas, Lúcia Helena de Souza, Luciana Kuk, Márcia Marques, Maria Eugênia de Menezes, Neomisia Silvestre, Pombas Urbanas, Rogério Eduardo Alves, Samuel Paiva e Zenaide Paludo. 


\section{CorpoCavalo}

Por que não nos fizeram os deuses nascer como os cavalos, fortes e pulando, já em pé?

Por que esta pele tão frágil?

Por que este corpo tão mole que precisa aprender longamente a maleabilidade de cada vértebra até se por de pé?

Guarda na pele Da memória indelével Essa primeira roupa Tecida de vitórias e fracassos De ser um animal À beira do naufrágio

No mar dos seus temores

É quando sonha como no sonho Ser um grande cavalo e nada mais

Sonia Rangel 


\section{RESUMO}

Esta dissertação circunscreve os mecanismos de organização e criação de três grupos teatrais radicados no distrito de Barão Geraldo, Campinas, SP. Os dados são coletados a partir de observações, anotações de campo e entrevistas. Como forma narrativa, procuramos colocar em relevo a subjetividade entredita nos discursos e práticas. Retraçamos o percurso histórico do lugar e dos três grupos eleitos para a análise: o Lume - Núcleo Interdisciplinar de Pesquisas Teatrais, a Boa Companhia de Teatro e o Barracão Teatro. A partir dessas trajetórias, descortinamos um panorama bastante peculiar do fazer artístico em território de reminiscências rurais, outrora ocupado por fazendas de café e de cana-de-açúcar, entre os séculos XIX e XX, e convertido à modernidade com a chegada do campus da Universidade Estadual de Campinas (UNICAMP), na década de 1960. A maioria dos atores-criadores estuda ou ministra aula no Departamento de Artes Cênicas do Instituto de Artes. Primeiro como laboratório de movimentos corporais, depois como núcleo, o Lume é vinculado à instituição e, após anos de reivindicação, obtém infraestrutura razoável para manter-se. Boa Companhia e Barracão Teatro seguem caminhos independentes, mas seus profissionais também têm a universidade como referência. Os artistas fundam e sistematizam uma rigorosa pesquisa voltada à arte de ator contemplada em diferentes linhagens, como a máscara, o clown e a mimese corpórea. Seus processos transparecem uma deontologia para o ofício que abraçam. Os três grupos possuem sedes localizadas em Vila Santa Isabel. Atualmente, somando outros bairros de Barão Geraldo, existem pelo menos mais 12 coletivos em atividade. Eles sintonizam a crescente produção do Teatro de Grupo no Brasil, a partir dos anos 1990, cuja tônica são os chamados espetáculos experimentais gerados em modo colaborativo e fomentados por políticas culturais que valorizam a cidadania. A contradição evidente dessa cultura de grupo, no distrito, é a extrema dificuldade em cativar o espectador vizinho, os nativos, que também se autoexcluem por associar o teatro à UNICAMP, herança do choque socioeconômico de sua implantação. Isso relativiza a vitória artística e chama aos desafios da vida artística em comunidade.

Palavras-chave: Política Cultural; Teatro; Teatro de Grupo; Teatro Comunitário; Cidadania. 


\begin{abstract}
This work describes the mechanism of organization and creation of three theater groups from a small town called Barão Geraldo located in the city of Campinas, São Paulo, Brazil. The data were collected through observation and interviews. In a narration form we aimed to detach the subjectivity in the discourses and practices of those groups. We traced the historical background of the town and of the groups: Lume - Núcleo Interdisciplinar de Pesquisas Teatrais, Boa Companhia de Teatro e Barracão Teatro. From a historical perspective we exposed a broad and peculiar view of making art in an area where coffee and sugar cane farms existed between XIX and XX centuries and which was occupied by Campinas State University in the 1960's bringing some modernity to the space, but also some social and economical shock. Most of the actors-creators study or teach at Departamento de Artes Cênicas do Instituto de Artes (Institute of Art). Lume became part of the University first as a lab for studying and training the body movements, then as an interdisciplinary center of theatrical research and after some struggle it has some institutional support to keep their work. Boa Companhia and Barracão follow independents paths, but their workers have the university as a reference. The artists found and systematize a meticulous research towards the art of the actor, through the study of masks, the clown art and the body mimesis. Their processes display a deontoly to their work. The three groups have their offices in Santa Isabel Village. Nowadays, there are at least 12 collectives working in the surroundings of Barão Geraldo. They harmonize with the increasing theater group production in Brazil since the 1990's, which are called 'experimental spectacle' created collectively and motivated by cultural policies which focus on citizenship. The evident contradiction of a group culture is the difficulty in captivating the local public, who exclude themselves because of the impact the University had on them in the past. This exhilarates an artistic victory and challenges the life of art in the community.
\end{abstract}

Key-words: Cultural Policy, Theater, Collective Drama Groups, Community Theater, Citizenship. 


\section{SUMÁRIO}

Dedicatória................................................ IV

Agradecimentos...................................................... $\quad \mathrm{V}$

Resumo............................................................... VII

Abstract..................................................................... VII

Introdução.................................................................... 001

\section{Capitulo I}

1.1. Panorama em processo do Teatro de Grupo no Brasil..... 012

1.2. Por uma ciência de ator.............................................. 019

\section{Capítulo II}

2.1. O distrito, a universidade, os artistas e os nativos............ 025

2.2. As lides acadêmicas............................................. 031

2.3. Parceiros de ofício..................................................... 036

2.4. Variação de um Teatro Comunitário.............................. 040

2.5. Eu troco, tu troca, nóis troca: o Teatro Comunitário como

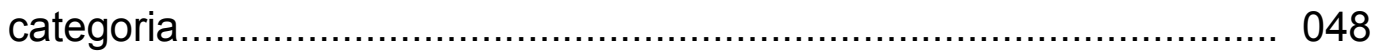

2.6 Feverestival independente...................................... 052

\section{Capítulo III}

3.1. Três grupos em busca de um ator................................ 060

3.2. Modos de opinião..................................................... 070

3.3. Modos de produção.................................................. 074

3.4. Modos de forjar................................................... 079

\section{Considerações finais}

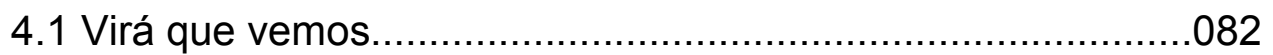


5. Referências bibliográficas.

.092

6. Apêndices

6.1 Depoimentos.

.098

7. Anexos

7.1 Grupos e espaços em Barão Geraldo 